\title{
ANTIBACTERIAL EFFECT OF ALOE VERA AND GLASS IONOMER MODIFIED BY ALOE VERA ON STREPTOCOCCUS MUTANS
}

\author{
Mayada S. Sultan *
}

\begin{abstract}
Objective: To evaluate the antibacterial effect of Aloe Vera and glass ionomer modified by Aloe Vera on Streptococcus mutans in comparison to Chlorhexidine.

Methods: A total of fifty samples were used in the study and divided into 5 groups according to the materials used $(\mathrm{n}=10)$ Group 1:2\% Chlorhexidine gluconate(CHX); Group 2: Aloe Vera (AV); Group 3: Glass ionomer (GI); Group 4: $2 \%$ Chlorhexidine gluconate added to glass ionomer $(\mathrm{CHX}+\mathrm{GI})$ and Group 5: Aloe Vera added to glass ionomer $(\mathrm{AV}+\mathrm{GI})$ and. The antibacterial effect of each group were assessed by disc diffusion methods after two-time intervals: 24 and 48 hours. Data were tabulated and statistically analyzed using Two-way ANOVA followed by Bonferroni's post-hoc test.
\end{abstract}

Results: There was a statistically significant difference between the materials used on inhibition zone diameter after 24 and 48 hours. CHX showed the statistically significantly highest mean inhibition zone diameter followed by AV $>$ CHX + GI $>$ AV + GI. GI group showed the lowest mean inhibition zone diameter with a statistically significantly.

Conclusion: Aloe Vera is beneficial in the inhibition of Streptococcus mutans growth up to 48 hours. The incorporation of Aloe Vera in glass ionomers seems to improve the antibacterial activity of glass ionomer restoration.

KEY WORDS: Aloe Vera, Chlorhexidine, Glass Ionomer, Streptococcus mutans, Antibacterial Activity.

\section{INTRODUCTION}

Dental caries is one of the most common diseases affecting oral health. It is a multifactorial lesion related to the interaction between oral microorganisms, teeth and diet. ${ }^{(1)}$ The incidence of dental caries is depending on Streptococcus mutans which is the main factor that trigger dental caries. (2) These anaerobic microorganisms adhere to the tooth surface initiating plaque formation through their ability to synthesize and bind extracellular polysaccharides using glucosyltransferase enzyme.

\footnotetext{
* Lecturer, Operative Dentistry Department, Faculty of Dentistry, Assiut University
} 
Streptococcus mutans also are able to metabolize sucrose into lactic acid which cause a significant drop in salivary $\mathrm{pH}$ below the critical $\mathrm{pH}(5.5){ }^{(3,4)}$

The continuous and repeated decrease in salivary $\mathrm{pH}$ can cause demineralization of the inorganic tooth structure and eventually tooth decay. Therefore, reducing these cariogenic microorganisms is beneficial in caries prevention. ${ }^{(5,6)}$ For many years, scientific research continues to make progress in identifying the best practices for preventing dental caries. Minimal intervention dentistry focuses on the least invasive treatment options to preserve the natural tooth structure as much as possible. ${ }^{(7,8)}$

Glass ionomer cement (GIC) is characterized by its antibacterial properties and fluoride release. The literature has proofed that the fluoride released from GIC is not sufficient to diminish the cariogenic bacteria. Furthermore, these bacteria are able to survive and remain viable under GIC restorations up to two years resulting in development of secondary caries. ${ }^{(9,10)}$ Consequently, the use of cavity cleansers before the placement of the restorations are promising in the field of contemporary minimal intervention dentistry. ${ }^{(11)}$

Chlorhexidine (CHX) is a broad-spectrum antimicrobial effective against gram negative and gram positive bacteria. It is very effective mouthwash in reducing gingivitis and plaque accumulation. ${ }^{(12)}$ Also Chlorhexidine and Chlorhexidine digluconate are widely used as cavity disinfectants due to their powerful effect in reducing the cariogenic microorganisms. ${ }^{(13)}$ It exerts the antibacterial action by binding to the dentin amino acids. ${ }^{(14)}$ However, the undesirable side effects of $\mathrm{CHX}$ such as brownish discoloration of teeth and restorations, mucosal soreness and desquamation and taste disturbances limit its clinical use. ${ }^{(15)}$ Further researches were developed to find alternative sources of natural antibacterial agents with a focus on safety for humans and efficacy in the treatment and prevention of dental caries. ${ }^{(11,13,16)}$

Aloe Vera (AV) is an equatorial plant grown easily in hot and dry weather of Africa and Asia. It has been used therapeutically for a long time due to its peculiar benefit. ${ }^{(17)}$ Aloe Vera has various pharmacological actions such as anti-fungal, antiviral, antiinflammatory, antibacterial, antioxidant, antitumor activities, detoxifier, hypoglycemic, antiseptic and tonic for the nervous system. ${ }^{(6,18)}$

Aloe Vera has been used in dentistry and showed good results in treatment of periodontitis, lichen planus, oral ulceration, oral candidiasis, ${ }^{(19,20)}$ denture stomatitis, disinfectant in endodontic treatments, plaque control, healing of socket, denture adhesive, and anti-caries agent. ${ }^{(21,22)}$ It has been successfully applied in toothpastes ${ }^{(6)}$, mouthwashes, and dental floss. ${ }^{(5,23)}$ Although Aloe Vera have been used in dentistry for various purposes, till now no study has been conducted to investigate its effect after incorporation to dental restorative materials as glass ionomer restoration. Therefore, this in vitro study was designed to evaluate the antibacterial effect of Aloe Vera and glass ionomer modified by Aloe Vera on Streptococcus mutans.

\section{MATERIALS AND METHODS}

\section{Materials used in the study:}

In the current study three different materials were used; fresh mature Aloe Vera, 2\% chlorhexidine gluconate (commercially available in syringe form, Consepsis, Ultradent) and Amalgomer TM advanced glass ionomer esthetic anterior restoration (Advanced Health Care Ltd, Tonbridge, Kent, UK) water mix type.

\section{Sample grouping:}

A total of fifty samples were used in the study and divided into 5 groups according to the materials used ( $\mathrm{n}=10)$ Group1: 2\% Chlorhexidine gluconate(CHX); Group 2: Aloe Vera (AV); Group 3: Glass ionomer (GI); Group 4: $2 \%$ Chlorhexidine gluconate added to glass ionomer $(\mathrm{CHX}+\mathrm{GI})$ and Group 5: Aloe Vera added to glass ionomer $(\mathrm{AV}+\mathrm{GI})$. The antibacterial effect of each group were assessed after two-time intervals: 24 and 48 hours. 


\section{Preparation of Aloe Vera:}

Fresh mature Aloe Vera leaves about $30-50 \mathrm{~cm}$ were selected and washed with distilled water then their spines were chopped. The thick epidermis was removed to collect the solid mucilaginous gel in a sterile container. The thick straw-colored gel crushed in a sterile mortar and pestle then the gel squeeze using a sterilized piece of gauze to collect Aloe Vera juice in a sterile syringe. ${ }^{(20,24)}$

A filter paper discs of $5 \mathrm{~mm}$ diameter were prepared (Whatman filter paper No.1) and placed in a petri dish for sterilization in a hot air oven for two hours at $160^{\circ} \mathrm{C}$. Regarding Group1 (CHX) and Group $2(\mathrm{AV})$, the paper discs were immersed in $20 \mathrm{~mL}$ of $\mathrm{CHX}$ and $20 \mathrm{~mL}$ of AV respectively till saturation with the solutions. This has been done to avoid the spread of the solutions in a wider diameter in the plate to standardize the sample size $(5 \mathrm{~mm}$ diameter) for all tested groups.

\section{Preparation of glass ionomer specimens:}

Glass ionomer specimens were made using a sterilized custom split Teflon mold ( $5 \mathrm{~mm}$ in diameter $\mathrm{x} 2 \mathrm{~mm}$ in height). For specimens' preparation, sterilized glass slide covered with a Mylar strip (Stripmat, POLYDENTIA, CH-6805 Mezzovico, Switzerland) was used. The glass ionomer powder and the distilled water were proportioned according to the manufacturer' instructions and mixed until a homogenous mix was obtained. The materials were packed into the mold as one increment then covered with another Mylar strip and a glass slide, then pressed for 10 seconds to expel the excess material and achieve a uniform smooth surface. Glass ionomer mix was left into the mold till complete setting. Regarding Group 4 (CHX+ GI) and Group $5(\mathrm{AV}+\mathrm{GI})$, the glass ionomer specimens were prepared with the same procedures as mentioned before except that the glass ionomer powder were mixed with $\mathrm{CHX}$ and AV respectively instead of distilled water.

\section{Testing of antibacterial activity:}

ATCC 25175 Type strain Streptococcus mutans (16S rRNA gene, Serotype c. carious dentin) were obtained from MIRCEN (Microbiological Resources Centre, Cairo, Egypt) and used in this in vitro study. Bacteria were cultured at $37^{\circ} \mathrm{C}$ overnight in Trypticase Soy agar (BD 236950, Difco ${ }^{\mathrm{TM}}$, USA) and used as inoculums. The McFarland 0.5 turbidity standard (Densimat, BioMerieux, France) was used to determine the turbidity of the suspension. On that absorbance, the concentration of bacteria is standardized to about $1 \mathrm{x} \mathrm{CFU/ml} \mathrm{and} \mathrm{used} \mathrm{as} \mathrm{a}$ working microbial solution.

A total $100 \mu$ l of the previously prepared working microbial solutions was spread evenly over blood agar (blood agar base (sheep) CM0854, Oxiod, UK) plate (TSA, Difco, USA). The plates were incubated at $37^{\circ} \mathrm{C}$ a bacteriological incubator. The antibacterial effect for all groups were appraised by measuring the diameter of bacterial growth inhibition zones after 24 and 48 hours. The diameter of the bacterial growth inhibition zones was measured in millimeters using an electronic digital caliper (STECO, Germany) at three different points to obtain three measurements for each specimen.

\section{Statistical Analysis}

Numerical data were explored for normality by checking the distribution of data and using tests of normality (Kolmogorov-Smirnov and Shapiro-Wilk tests). Data showed parametric distribution. Data were presented as mean, standard deviation (SD) and $95 \%$ Confidence Interval for the mean $(95 \% \mathrm{CI})$ values. Two-way Analysis of Variance (ANOVA) was used to study the effect of material, time and their interaction on mean inhibition zone diameter. Bonferroni's post-hoc test was used for pair-wise comparisons when ANOVA test is significant. The significance level was set at $\mathrm{P} \leq 0.05$. Statistical analysis was performed with IBM ${ }^{\circledR}$ SPSS ${ }^{\circledR}$ Statistics Version 20 for Windows. 


\section{RESULTS}

Two-way ANOVA results showed that material, time as well as the interaction between the two variables had a statistically significant effect on mean inhibition zone diameter (table 1). Since the interaction between the variables is statistically significant, so the variables are dependent upon each other.

Descriptive statistics of inhibition zone diameter at the two follow up times regardless of material were represented by mean, standard deviation (SD), 95\% Confidence Interval values in table (2). There was a statistically significant difference between the two follow up times ( $P$-value $<0.001$, Effect size $=0.625)$. Pair-wise comparisons between the time periods revealed that 48 hours showed statistically significantly higher mean inhibition zone diameter than 24 hours.

All the five groups showed antibacterial activity. Figure (1) showed the zones of inhibition against
Streptococcus mutans around the tested material. Table (3) and figure (2) showed that there was a statistically significant difference between the materials used on inhibition zone diameter after 24 and 48 hours. Pair-wise comparisons between the materials revealed that $\mathrm{CHX}$ showed the statistically significantly highest mean inhibition zone diameter. AV showed statistically significantly lower mean inhibition zone diameter followed by CHX + GI then AV + GI group with a statistically significant difference between these groups. GI group showed the lowest mean inhibition zone diameter with a statistically significantly.

As regarding the effect of time, there was a statistically significant difference between the two follow up times. The mean inhibition zone diameter after 48 hours showed statistically significantly higher mean value than 24 hours in CHX group; AV group and $\mathrm{CHX}+\mathrm{GI}$ group. While in $\mathrm{AV}+\mathrm{GI}$ group and GI group, there was no statistically significant difference between the two follow up times.

TABLE (1): Two-way ANOVA results for the effect of different variables on mean inhibition zone diameter

\begin{tabular}{ccccccc}
\hline $\begin{array}{c}\text { Source of } \\
\text { variation }\end{array}$ & $\begin{array}{c}\text { Type III Sum of } \\
\text { Squares }\end{array}$ & Df & Mean Square & $F$-value & $P$-value & $\begin{array}{c}\text { Effect size } \\
\text { (Partial } \text { eta squared) }\end{array}$ \\
\hline Material & 987.312 & 4 & 246.828 & 2915.798 & $<0.001^{*}$ & 0.997 \\
Time & 5.638 & 1 & 5.638 & 66.603 & $<0.001^{*}$ & 0.625 \\
$\begin{array}{c}\text { Material x Time } \\
\text { interaction }\end{array}$ & 3.469 & 4 & 0.867 & 10.246 & $<0.001^{*}$ & 0.506 \\
\hline
\end{tabular}

$d f:$ degrees of freedom $=(n-1), *$ : Significant at $P \leq 0.05$

TABLE (2): The mean, standard deviation (SD), 95\% Confidence Interval values and the results of comparison between the inhibition zone diameters at the two time intervals regardless of material

\begin{tabular}{|c|c|c|c|c|c|}
\hline \multicolumn{2}{|c|}{24 hours } & \multicolumn{2}{|c|}{48 hours } & \multirow{2}{*}{$P$-value } & \multirow{2}{*}{$\begin{array}{c}\text { Effect size (Partial } \\
\text { eta squared) }\end{array}$} \\
\hline Mean (SD) & $95 \%$ CI & Mean (SD) & $95 \% \mathrm{CI}$ & & \\
\hline $7.44(4.35)$ & $7.32-7.56$ & $8.11(4.74)$ & $8-8.23$ & $<0.001 *$ & 0.625 \\
\hline
\end{tabular}

*: Significant at $P \leq 0.05$ 


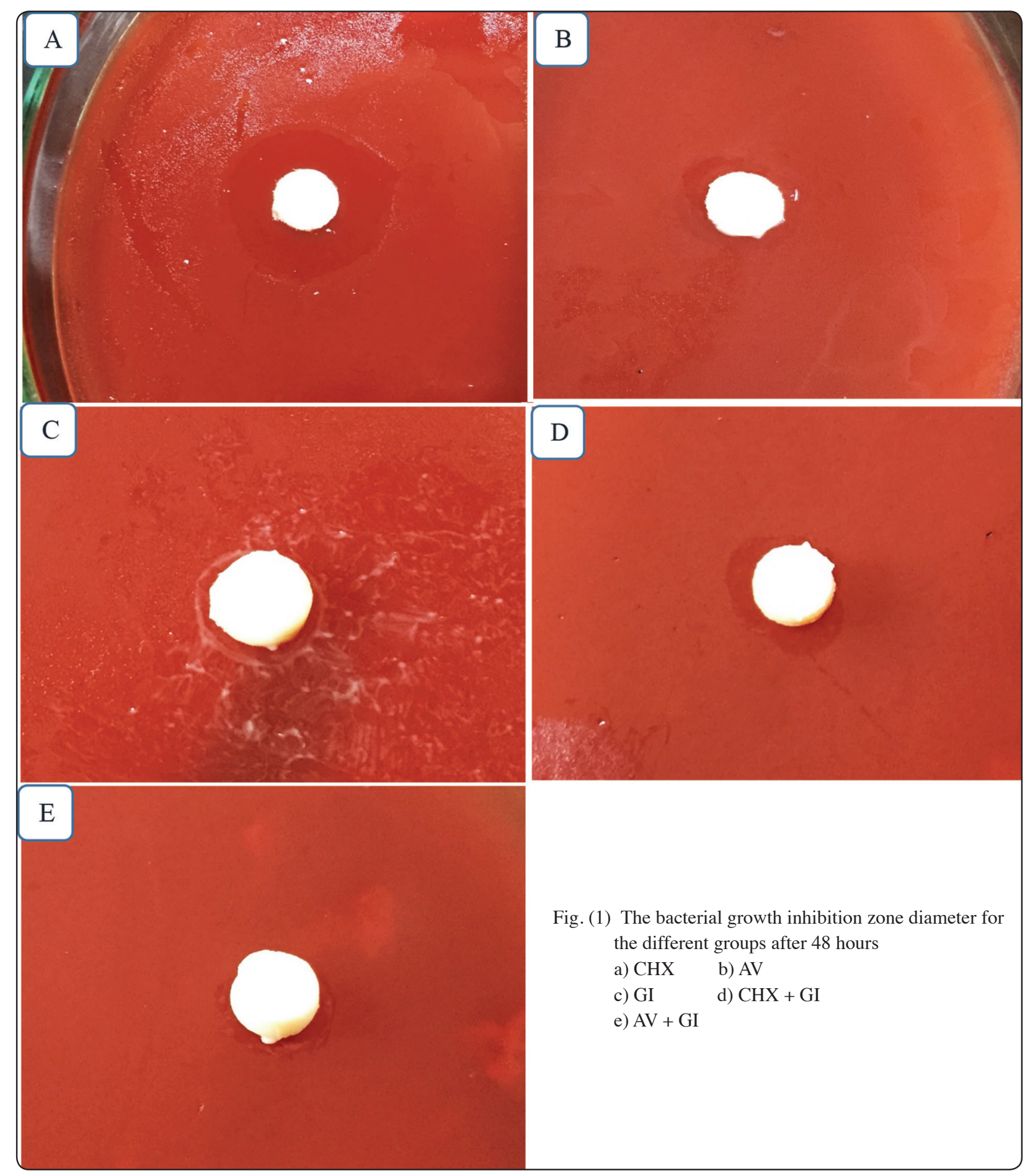


TABLE (3) The mean, standard deviation (SD), 95\% Confidence Interval values and the results of comparison between the inhibition zone diameters for the different interactions

\begin{tabular}{|c|c|c|c|c|c|c|}
\hline \multirow{2}{*}{ Material } & \multicolumn{2}{|c|}{24 hours } & \multicolumn{2}{|c|}{48 hours } & \multirow{2}{*}{$\begin{array}{c}P \text {-value } \\
\text { (Between } \\
\text { times) }\end{array}$} & \multirow{2}{*}{$\begin{array}{c}\text { Effect size } \\
\text { (Partial eto } \\
\text { squared) }\end{array}$} \\
\hline & Mean (SD) & $95 \% \mathrm{CI}$ & Mean (SD) & $95 \% \mathrm{CI}$ & & \\
\hline CHX & $15.31(0.35)^{\mathrm{A}}$ & $15.04-15.57$ & $16.44(0.12)^{\mathrm{A}}$ & $16.18-16.7$ & $<0.001 *$ & 0.487 \\
\hline AV & $7.71(0.24)^{\mathrm{B}}$ & $7.44-7.97$ & $8.73(0.47)^{\mathrm{B}}$ & $8.47-8.99$ & $<0.001 *$ & 0.436 \\
\hline GI & $2.71(0.2)^{\mathrm{E}}$ & $2.45-2.98$ & $2.53(0.14)^{\mathrm{E}}$ & $2.27-2.79$ & 0.323 & 0.024 \\
\hline $\mathrm{CHX}+\mathrm{GI}$ & $6.13(0.53)^{\mathrm{C}}$ & $5.87-6.4$ & $7.22(0.27)^{\mathrm{C}}$ & $6.96-7.49$ & $<0.001 *$ & 0.467 \\
\hline $\mathrm{AV}+\mathrm{GI}$ & $5.35(0.13)^{\mathrm{D}}$ & $5.09-5.61$ & $5.64(0.09)^{\mathrm{D}}$ & $5.38-5.91$ & 0.118 & 0.060 \\
\hline $\begin{array}{c}P \text {-value } \\
\text { (Between } \\
\text { materials) }\end{array}$ & \multicolumn{2}{|c|}{$<0.001 *$} & \multicolumn{2}{|c|}{$<0.001 *$} & & \\
\hline $\begin{array}{l}\text { Effect size } \\
\text { (Partial eta } \\
\text { squared) }\end{array}$ & \multicolumn{2}{|c|}{0.993} & \multicolumn{2}{|c|}{0.994} & & \\
\hline
\end{tabular}

*: Significant at $P \leq 0.05$, Different superscripts in the same column are statistically significantly different

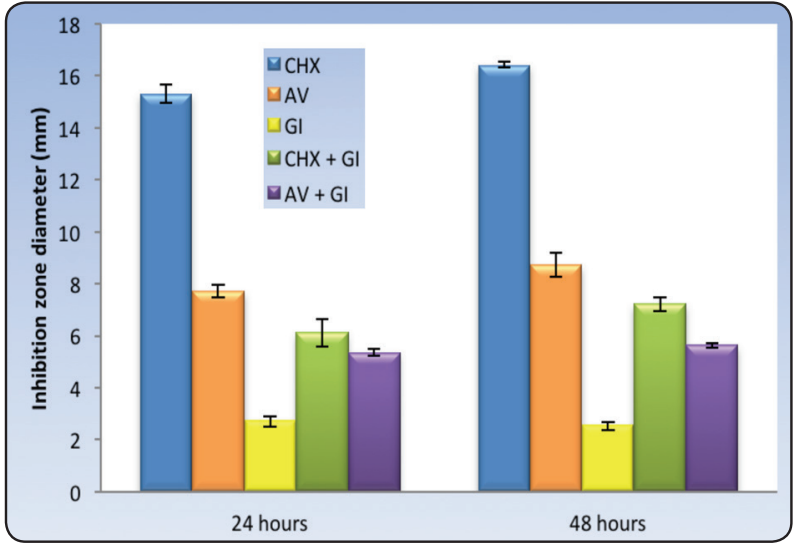

Fig. (2) Bar chart representing mean and standard deviation values for inhibition zone diameters with different interactions of variables

\section{DISCUSSION}

The present study was conducted to evaluate the antibacterial effect of Aloe Vera and glass ionomer modified by Aloe Vera on Streptococcus mutans.

Dental caries development and progression are depending on the presence of acidic media. Streptococcus mutans is considered a main cause for acid production through metabolizing the dietary sucrose and subsequent demineralization of tooth tissues. ${ }^{(5)}$ Although this demineralized dentin contains bacteria, it can be left intact to maintain the pulp vitality. According to the minimally invasive dentistry, such treatment is acceptable providing the use of cavity disinfectant against these cariogenic bacteria. Also, it depends on the use of glass ionomer cements that characterized by anti-bacterial properties and fluoride release. ${ }^{(8,25)}$

The released fluoride contributes reduction in the number of residual bacteria and remineralization of soft dentin. However, viable bacteria have been found in the remaining affected dentin after different periods of evaluation, even after the removal of infected dentin and adequate sealing. ${ }^{\left({ }^{8} 10\right)}$ Therefore, the researchers enhance the antibacterial properties of GICs by adding antibacterial agents as antibiotics (9) and chlorhexidine. ${ }^{(26,27)}$ Although chlorhexidine was able to reduce the residual bacteria but it has adverse effects on the microtensile and shear bond strengths. (11) Consequently, the use of natural antibacterial such as Miswak and proplis become a growing trend in modification of dental restorations to avoid the side effects of the chemical one. ${ }^{(28)}$ 
In the present study, all the tested materials showed statistically significant effect on mean inhibition zone diameter after 24 and 48 hours. The chlorhexidine gluconate $2 \%$ showed the statistically significantly highest mean inhibition zone diameter. Chlorhexidine has a proven antibacterial effect and it was used as cavity disinfectant at this concentration. ${ }^{(14,15)}$ Chlorhexidine enters bacterial cytoplasm destroying the cell membrane integrity. This leads to an increase in the bacterial cell wall permeability and osmotic imbalance. Chlorhexidine binds to phospholipids and dentin amino acids which cause damage to the cell molecular weight. Furthermore, it precipitates the phosphate groups in the cytoplasm causing coagulation and leakage of intracellular components which results in bacterial lysis and death. ${ }^{(5,14)}$

The results of this study were in accordance with Sancakli et al., $2018^{(14)}$ who evaluated methods of antibacterial surface pretreatment against $\mathrm{S}$. mutans within the infected dentin surface. They found that antibacterial dentin bonding and chlorhexidine have the highest antibacterial effects when compared with Er:YAG Laser and ozone.

In this in vitro study Aloe Vera showed statistically significantly effect on the mean inhibition zone diameter. This antimicrobial activity is attributed to the pharmacologically active component of Aloe Vera. The fresh Aloe Vera leaves excrete a mucilaginous colorless gel that contains high percent of water (98-99\%) and about 1-2\% active compounds. ${ }^{(21)}$ It contains about 75 active ingredients as amino acids, salicylic acid, anthraquinones, anthracine, Aloe mannan, phenols, Aloe-emodin, polysaccharides, resistanol, aloetic acid, Aloin, vitamins, lignins, aloeride, sterols, antranol and saponin. Free Anthroquinones like emodin and aloin (a bitter-tasting yellow compound) are potent antimicrobial agents. ${ }^{(17,29)}$

Aloe Vera compounds like anthraquinones and saponin have direct antibacterial activities as they can inhibit protein synthesis from bacterial cells.
This results in disruption of membrane permeability so the bacterial growth is inhibited. ${ }^{(30)}$ Aloe Vera gel also can exert indirect bactericidal activity by some other components, such as acemannan through stimulation of leukocytes phagocytosis. Saponin has an antiseptic effect as it can dissolve the lipoprotein in the bacterial cell membrane. This is causing damage the cell membrane of bacteria results in bacterial lysis and death. ${ }^{(29,31)}$

This result was in agreement with Prabhakar et al., $2015{ }^{(11)}$ who evaluated the efficacy of Aloe Vera and propolis as cavity disinfecting agents for minimally invasive hand excavation of dental caries. They found Aloe Vera extracts showed a significant reduction in the bacterial counts. Fani and Kohanteb $2012{ }^{(20)}$ found that the use of Aloe Vera gel at optimum concentrations in toothpastes or mouthwashes could be useful for prevention of dental caries and periodontal disease.

On the other hand, this result was in contradiction with Sreekumar and Hegde $2018{ }^{(27)}$ as they found that Aloe Vera failed to show any zone of inhibition against streptococcus mutans when compared with other herbal products. This may be attributed to that Aloe Vera extracts are highly technique sensitive and improper processing procedures lead to loss of its active ingredients.

In this in vitro study Aloe Vera showed statistically significantly lower mean inhibition zone diameter in comparison to CHX. This may attribute to that the mechanism of action of Aloe Vera that works by gradually damaging to the cell membrane of bacteria which is not progressive as chlorhexidine. ${ }^{(5)}$

These findings were in agreement with Nonong et al., $2016{ }^{(5)}$ who reported a significant difference between Chlorhexidine and Aloe Vera in decreasing the number of Streptococcus mutans colonies. Also, Patri and Sahu $2017^{(24)}$ compared the efficacy of herbal antibacterial agents (Tea Tree Oil and Aloe Vera) with commercially available $2 \%$ chlorhexidine as cavity disinfectant used for minimally invasive 
dentistry. They found that $2 \%$ chlorhexidine showed the highest reduction in Total Viable Count followed by $1 \%$ tea tree oil and aloe Vera gel.

Gupta et al., 2014 ${ }^{(29)}$ observed that the Aloe Vera mouth rinse has equal effect as $0.2 \% \mathrm{CHX}$. In the present study, 2\% CHX showed better antibacterial effect than the Aloe Vera juice. This could be attributed to the difference in $\mathrm{CHX}$ concentration.

The present study showed that, there was a statistically significant difference between the two follow up times. The mean inhibition zone diameter after 48 hours showed statistically significantly higher mean value than 24 hours in CHX and AV groups. This might be attributed to the difference in rate of diffusion between $\mathrm{CHX}$ and $\mathrm{AV}$. This finding was in agreement with Nonong et al., $2016^{(5)}$ who reported that Aloe Vera and Chlorhexidine showed effective decreased in the Streptococcus mutans colonies after 2 days.

GI group showed the statistically significantly lowest mean inhibition zone diameter. The antibacterial activity of glass cements is one of the most appealing properties that has a direct correlation with the amount of fluoride release. Fluoride release may be influenced by many factors such as the released fluoride and other ions, the chemical composition of glass ionomer and low $\mathrm{pH}$ value during setting. It appears to be the most likely cause of the inhibitory effect on acid production and it also affecting the bacterial metabolism. ${ }^{(25,27)}$

This finding was in agreement with ŁuczajCepowicz et al., $2014^{(25)}$ who determined the antibacterial activity of four glass ionomer cements against Streptococcus and Lactobacillus. They reported that there was different antibacterial activity of glass ionomer cements observed depending on the cement, time of evaluation and bacterial strain. Also, Bariker and Mandroli $2016{ }^{(32)}$ who evaluated the antibacterial activity of Fuji VII and Amalgomer CR against streptococci mutans. They reported that Amalgomer CR had the most antibacterial effect against S. mutans.
In GI group, there was no statistically significant difference between the two follow up times. This may be due to the initial low $\mathrm{pH}$ of the cements during setting which lasting from several minutes to 24 hours till reach the neutrality. ${ }^{(10)}$

In this study $\mathrm{CHX}+\mathrm{GI}$ showed higher mean inhibition zone diameter GI with a statistically significant difference between these groups. This might be attributed to interaction between the cationic $\mathrm{CHX}$ molecule and the fluoride ion resulting in the precipitation of salts with lower solubility. ${ }^{(26)}$ The mean inhibition zone diameter after 48 hours showed statistically significantly higher mean value than 24 hours in CHX + GI group. This may be due to the elution rate of the CHX from the GI, where synergism has been appeared to happen between fluoride and the cationic CHX. ${ }^{(28)}$

This results were in accordance Yadiki et al., $2016{ }^{(26)}$ compared the antimicrobial properties of two commercially available glass ionomer cements with and without chlorhexidine gluconate on strains of streptococci mutans. They confirmed that the addition of chlorhexidine gluconate to the tested cements produced a restorative material with increased antimicrobial properties. Duque et al., $2018{ }^{(33)}$ who found that the incorporation of chlorhexidine to glass ionomer cements GIC increased the in vitro antimicrobial activity, without changing chemical-mechanical properties of GIC and odontoblast-like cell viability.

In the present study, A V + GI showed statistically significantly higher mean inhibition zone diameter than GI. As the combined effect of Aloe Vera with the glass ionomer was not available in literatures, this may be due to the presence of anthraquinones that react with fluoride released from glass ionomer cement to form fluoroquinolones compound. These compounds are highly soluble in acidic $\mathrm{pH}$ and have greatly activity against many Gram positive bacteria. ${ }^{(34)}$ Therefore, the acid base reaction of glass ionomer cement (initial acidic $\mathrm{pH}$ ) enhance the solubility of fluoroquinolones. There was 
no statistically significantly effect on the mean inhibition zone diameter in Aloe Vera+ GI group after 24 and 48 hours. This might be due to the low $\mathrm{pH}$ value of glass ionomer cements during the initial setting and the stability of fluoroquinolones compound in high $\mathrm{pH}$.

To summarize, Aloe Vera as natural product has antibacterial effect against Streptococcus mutans that allow its use as a cavity disinfectant more affordable with no side effects than chlorhexidine. It has the ability to inhibit the growth of streptococci mutans. Also the incorporation of chlorhexidine gluconate and Aloe Vera to glass ionomer cements increased its antimicrobial properties.

\section{CONCLUSIONS}

Despite the limitations of this study, the following could be concluded:

1. Aloe Vera has an inhibitory effect on Streptococcus mutans up to 48 hours.

2. The incorporation of Aloe Vera in glass ionomers seemed to improve the antibacterial activity of glass ionomer.

\section{RECOMMENDATIONS}

1. Further long-term investigations assessing the antibacterial activity of Aloe Vera on Streptococcus mutans may be required.

2. Further investigations to evaluate the mechanical properties of glass ionomer modified by Aloe Vera.

\section{REFERENCES}

1. Ravi SB, Nirupad S, Chippagiri P, Pandurangappa R. Antibacterial effects of natural herbal extracts on Streptococcus mutans: Can they be potential additives in dentifrices? Int J Dent. 2017; 2017(10):1- 5.

2. Dziedzic A, Wojtyczka RD, Kubina R. Inhibition of oral Streptococci growth induced by the complementary action of berberine chloride and antibacterial compounds. Molecules. 2015; 20:13705-13724.
3. Millo G, Juntavee A, Ratanathongkam A, Nualkaew N, Peerapattana J, Chatchiwiwattana S. Antibacterial inhibitory effects of Punica Granatum gel on cariogenic bacteria: An in vitro Study. Int J Clin Pediatr Dent. 2017; 10 (2):152-157.

4. Jazaeri M, Pakdel F, Rezaei-Soufi L, Abdolsamadi H, Rafieian N. Cariostatic effect of green tea in comparison with common anticariogenic agents: An in vitro study. J Dent Res Dent Clin Dent Prospects. 2015; 9 (1): 44- 48.

5. Nonong Y H, Satari M H, Indriyanti R, Patawulandari S. Antibacterial test between Aloe Vera and Chlorhexidine based on the number of colony of Streptococcus mutans ATCC 25175 in vitro. Int J Sci Res. 2016; 5 (1): 1379 1385.

6. Balaji Subramaniyan R, Kayalvizhi G. A scientific approach to evaluate the anticaries effect of Aloe Vera gel toothpaste in experimental animal model. J Sci. 2016; 6 (11): 494-496.

7. Leal SC. Minimal intervention dentistry in the management of the paediatric patient. Br Dent J. 2014; 216 (11): 623627.

8. Alencar CRB, Silva OL, MendoÇa FL, Andrade FJP. Strategies for control and treatment of carious lesions in deciduous molars: a review of the literature. Rev Gaúch Odontol. 2016; 64(1): 62-69.

9. Mitta S, Soni H, Sharma DK, Mittal K, Pathania V, Sharma S. Comparative evaluation of the antibacterial and physical properties of conventional glass ionomer cement containing chlorhexidine and antibiotics. J Int Soc Prev Community Dent. 2015; 5: 268-275.

10. Fucio SBP, Paula AB, Sardi JCO, Duque C, CorrerSobrinho L, Puppin-Rontani RM. Streptococcus mutans biofilm influences on the antimicrobial properties of glass ionomer cements. Braz Dent J. 2016; 27(6): 681-687.

11. Prabhakar AR, Karuna YM, Yavagal C, Deepak BM. Cavity disinfection in minimally invasive dentistry - comparative evaluation of Aloe Vera and propolis: A randomized clinical trial. Contemp Clin Dent. 2015; 6 (1): S24- S31.

12. Varoni E, Tarce M, Lodi G, Arrassi A. Chlorhexidine (CHX) in dentistry: state of the art. Minerva Stomatol. 2012; 61:399-419.

13. Ferrazzano GF, Scioscia E, Sateriale D, Pastore G, Colicchio R, Chiara Pagliuca $\mathrm{C}$ et al. In vitro antibacterial activity of pomegranate juice and peel extracts on cariogenic bacteria. Biomed Res Int. 2017; 2152749: 1-7. 
14. Sancakli HS, Siso SH, Yildiz SO, Gökçe YB. Antibacterial effect of surface pretreatment techniques against Streptococcus Mutans. Niger J Clin Pract. 2018; 21:170-175.

15. Uzer Celik E, Tunac AT, Ates M, Sen BH. Antimicrobial activity of different disinfectants against cariogenic microorganisms. Braz. Oral Res. 2016; 30(1) e125: 1-6.

16. Wolde T, Kuma H, Trueha K, Yabeker A. Anti-bacterial activity of garlic extract against human pathogenic bacteria. J Pharmacovigil. 2018; 6(1)1000253: 1-5.

17. Sikarwar Mukesh S, Patil MB, Shalini S, Vishnu B Aloe Vera: plant of immortality. Int J Pharm Sci Res. 2010;1(1):7-10.

18. Barandozi FN. Antibacterial activities and antioxidant capacity of Aloe Vera. Bioorg Med Chem Lett. 2013; 3(1) 2858: $-3-5$.

19. Zagórska-Dziok M, Furman-Toczek D, Dudra-Jastrzębska M, Zygo K, Stanisławek A, Kapka-Skrzypczak L. Evaluation of clinical effectiveness of Aloe Vera - a review. Journal of Pre-Clinical and Clinical Research. 2017; 11(1): 86-93.

20. Fani M,Kohanteb J. Inhibitory activity of Aloe Vera gel on some clinically isolated cariogenic and periodontopathic bacteria. J Oral Sci. 2012; 54(1):15-21

21. Jain S, Rathod N, Nagi R, Sur J, Laheji A, Gupta N etal, Antibacterial effect of Aloe Vera gel against oral pathogens: An In-vitro study. J Clin Diagn Res. 2016;10(11): ZC41ZC44.

22. Dhaliwal JS, Gambhir RS, Sodhi SK, Shaheed G, Kifli NHM. Herbs and their use in oral care: A Review. BDJH. 2017; 7(1): 5-17.

23. Dhingra K. Aloe Vera herbal dentifrices for plaque and gingivitis control: a systematic review. Oral Dis. 2014; 20: 254-267.

24. Patri G, Sahu A. Role of herbal agents - Tea Tree Oil and Aloe Vera as cavity disinfectant adjuncts in minimally invasive dentistry- An in vivo comparative study. J Clin Diagn Res. 2017; 11(7): DC05-DC09.

25. Łuczaj-Cepowicz E, Marczuk-Kolada G, Zalewska A, Pawińska M, Leszczyńska K. Antibacterial activity of selected glass ionomer cements. Postepy Hig Med Dosw (online), 2014; 68: 23-28.

26. Yadik JV, Jampanapalli SR, Konda S, Inguva HC, Chimata VK. Comparative evaluation of the antimicrobial properties of glass ionomer cements with and without Chlorhexidine Gluconate. Int J Clin Pediatr Dent. 2016; 9(2):99-103

27. Sreekumar S, Hegde VK. Comparative evaluation of antibacterial effect of three commercially available herbal products against Streptococcus mutans: An in vitro study. J Indian Assoc Public Health Dent. 2018; 16 (1): 75-77.

28. Elgamily H, Ghallab O, El-Sayed H, Nasr M. Antibacterial potency and fluoride release of a glass ionomer restorative material containing different concentrations of natural and chemical products: An in-vitro comparative study. J Clin Exp Dent. 2018; 10(4): e312-e320.

29. Gupta RK, Gupta D, Bhaskar DJ, Yadav A, Obaid K, Mishra S. Preliminary antiplaque efficacy of Aloe Vera mouthwash on 4 day plaque re-growth model: Randomized control trial. Ethiop J Health Sci. 2014; 24(2): 139-144.

30. Gupta SJ. Aloe Vera: A natural perquisite to dental therapy. Cent Euro J Exp Bio. 2017; 5(2):24-30.

31. Hasan S, Asif S, Quadri S. Aloe Vera: general and dental implications - Overview of literature. Journal of Orofacial and Health Sciences. 2014; 5(1): 1-5.

32. Bariker RH, Mandroli PS. An in-vitro evaluation of antibacterial effect of Amalgomer CR and Fuji VII against bacteria causing severe early childhood caries. J Indian Soc Pedod Prev Dent. 2016; 34:23-29.

33. Duque C,Aida KL, Pereira JA, Teixeira GS, Caldo-Teixeira AS, Perrone LR et al,. In vitro and in vivo evaluations of glass-ionomer cement containing chlorhexidine for Atraumatic Restorative Treatment. J Appl Oral Sci. 2017;25 (5):541-550.

34. Sharma PC, Jain A, Jain S. Fluoroquinolone antibacterials: A review on chemistry, microbiology and therapeutic prospects. Acta Poloniae Pharmaceutica - Drug Research. 2009; 66 (6): 587- 604. 